\title{
DAR-SE EM VERTIGEM: UMA FILOSOFIA DO CORPO E DE SUAS SENSAÇÕES
}

\section{T. P. NÓBREGA}

UFRN. Programa de Pós-Graduação em Educação. Bolsista CAPES de Estágio Sênior - École Normale Supérieure/Paris. pnobrega@ufrnet.br

Resenha submetida em novembro/2014 e aceito em novembro/2014

DOI: 10.15628/holos.2014.2584

"Dar-se em Vertigem: as artes imersivas" é o livro recentemente publicado pelo filósofo francês Bernard Andrieu, autor de várias obras sobre a temática do corpo publicadas em língua francesa. Em língua portuguesa podemos encontrar "A Nova filosofia do corpo", editada pelo Instituto Piaget na Coleção Epistemologia e Sociedade (ANDRIEU, 2004).

O livro aborda a imersão experiencial que faz com que percamos nossas referências, como na vertigem, seja por meio de técnicas de privação e de estimulação sensoriais ou de situações inéditas, invasivas ou não. A interação é dinamizada na imersão, colocando-se o corpo em uma situação de plasticidade na qual ele poderá ou não atualizar potenciais endógenos e criar novos dispositivos neuronais e existenciais. "A vertigem interior que experimentamos estando incorporado na imagem, no meio ou em outra pessoa é produzida pela ativação de zonas cerebrais, mesmo se nosso corpo está na realidade imóvel diante de seu console, seu capacete, face a imagem ou aos elementos" (ANDRIEU, 2014, p. 17).

Os argumentos são bem documentados e enriquecidos com os relatos em primeira pessoa, incluindo àqueles do autor. Ao começar a leitura podemos nos deleitar com a epigrafe que dá o tom e que permeia todo o texto, qual seja, as sensações do corpo vivo e sua expressão como corpo vivido. O autor nos convida à leitura de sua obra nos oferecendo um trecho de Chronique d'hiver ${ }^{1}$ de Paul Auster e que merece aqui ser transcrito: "Talvez seja melhor deixar de lado as suas histórias por ora e tentar examinar a sensação de viver dentro deste corpo, desde o primeiro dia da sua vida do qual você se lembra até hoje. Um catálogo de dados sensoriais. O que poderia ser denominado fenomenologia da respiração" (AUSTER, 2014, p. 7;8). Esse trecho da crônica expressa de modo poético o que Bernard Andrieu propõe em seu livro, a saber: dar-se em vertigem, mergulhar no corpo e revelar uma cartografia de nossas paisagens internas ao mesmo tempo que nos faz criar novos esquemas corporais de empatia e relação com o mundo.

O autor faz uma leitura da obra Traité du vertige (Tratado da Vertigem), escrito por La Mettrie em 1737, destacando entre outros aspectos que os estados de alma são sempre correlativos àqueles do corpo. Nesse contexto, ser uma máquina animada - referência a obra L’homme Machine (O Homem Máquina) - diferentemente da máquina pensante do conexionismo, é fazer da reflexão uma propriedade da matéria organizada. Na vertigem, a perturbação sentida por uma perda de referência pode, como descreve La Mettrie, precipitar o sujeito em uma fluidez muito intensa que não lhe permite mais de se conter suficientemente para se manter no espaço e no tempo. "O sentimento de sua própria identidade torna-se precário quando da vertigem dado o desenvolvimento em si de uma sensação invasiva face ao controle consciente da sensibilidade. A perda de controle atinge o cérebro a ponto de perturbar a consciência e mergulhar o sujeito em seu corpo" (ANDRIEU, 201, p. 41). Essa vertigem pode se encontrar na velocidade, nas drogas, nos

\footnotetext{
${ }^{1}$ AUSTER, Paul. Diário de Inverno. Tradução de Paulo Henriques Brito. São Paulo: Companhia das Letras, 2014.
} 
surtos, no orgasmo, mas também em outras interações técnicas, as quais o autor denomina de artes imersivas, como os esportes radicais, as atividades circenses, a dança e a yoga, por exemplo.

Uma primeira nota a se fazer sobre o livro é a inversão do ponto de vista da filosofia do corpo. Ao invés do corpo vivido, tema primeiro da fenomenologia do corpo, o autor trata do corpo vivo. O que isso significa? Bernard Andrieu nos propõe mergulhar na profundidade do corpo e de suas sensações. Não se trata de descrever a experiência do corpo vivido, mas sim de se entregar a escuta do corpo, tal como acontece com a respiração, o batimento cardíaco, a circulação do sangue e muitos outros índices corporais que só podem chegar a dimensão da consciência, portanto do relato da experiência vivida, com um atraso que vai de 350 a 500 mil segundos da atividade cerebral. Assim, tomando como referência diversos estudos atuais obre o cérebro o autor afirma que há um atraso sobre o que se passa no corpo até que a sensação possa chegar a níveis de consciência e portanto dos relatos descritivos.

Nesse sentido, o filósofo nos apresenta um novo contexto em que o corpo vivo age a despeito do sujeito consciente por meio da motricidade de sua ação e que nem sempre é percebida pelo sujeito consciente a qual Bernard Andrieu nomeia "pré-motricidade". Esta se efetua através de sensações internas e que o sujeito ressente. Por meio da percepção o sujeito pode descrever essa atividade do corpo vivo, mas há uma incapacidade de objetiva-la inteiramente. Desse modo, o que o sujeito vive é sempre maior e mais abrangente do que ele pode dizer.

No contexto das sensações, a propriocepção e a exteriocepção exprimem uma função singular. "A propriocepção parece assegurar esse conhecimento do corpo em primeira pessoa através das sensações produzidas pela experiência do nosso corpo. Na exteriocepção, MerleauPonty precisa 'a consciência do corpo invade o corpo' através do estímulo” (ANDRIEU, 2014, p. 67). Há pois uma construção de referenciais sobre o movimento e sobre o espaço incarnado que corresponde ao uso que fazemos do corpo na ação. Propriocepção e exteriocepção são como notas melódicas que nos colocam nesse estado de escuta sensível em relação ao nosso corpo e a seu entorno. Bernard Andrieu aproxima essa noção de intercorporeidade ao contexto de uma ecologia do corpo, com ênfase nessa relação direta corpo e mundo, no qual a consciência e a linguagem racional não ocupam o lugar central.

Entre os conceitos apresentados para apoiar sua tese encontra-se a noção de intercorporeidade ${ }^{2}$ como sendo uma dimensão inconsciente que nos religa ao corpo e ao mundo mais diretamente. Essa noção cuja inspiração vem da obra de Merleau-Ponty. Com base nessas referências, o autor vai explorar a profundidade do corpo em relatos em primeira pessoa nas quais se destaca o risco de se sentir (ressentir), se dar a vertigem, mergulhar nas sensações como ocorre em situações de êxtase, de sofrimento ou de prazer ou em práticas esportivas difundidas entre adolescentes como o "parkour" ou outros rituais sociais como festas ou em casos como a anorexia.

Bernard Andrieu também se concentra em exemplos artísticos como o caso do circo e da dança. No circo, as sensações produzem um confiança corporal em que a dor e as lesões são o preço a pagar. Para ele, a dor, a lesão e o sofrimento colocam o artista em seu corpo, sendo um exemplo da noção de intercorporeidade e da ligação direta com essa realidade e que se configura como uma consciência empática.

\footnotetext{
${ }^{2} \mathrm{~A}$ noção de intercorporeidade também aparece nos esboços sobre o corpo e natureza para dizer da relação dos outros corpos humanos com os corpos-coisas e a penetração dos sensíveis. "As coisas como sendo aquilo que falta ao meu corpo" (MERLEAU-PONTY, 1995, p.281).
} 
O livro apresenta vários relatos de experiências imersivas a começar pelas vividas pelo próprio autor. Narrando sua própria experiência com a dança, bem como reportando-se a narrativas de coreógrafos como Boris Charmatz e sua abordagem radical da dança ou a outros artistas como Triswa Brow e Vanderkeybus, o filósofo interroga se é o corpo que dança ou se é a dança que o conduz em suas formas e movimentos. De fato, a dança não é somente modificação da matéria afim de exprimir uma forma. O corpo dançante está além de qualquer técnica e sempre haverá uma distância entre o que foi previsto e o que é vivido.

Mas, atenção! A dança é apenas uma das artes imersivas apresentadas na obra. O autor trata do circo, da yoga e de outras práticas que podem ser consideradas nesse ponto de vista de dispositivo imersivo como mergulho e aprofundamento nas sensações. "O aprofundamento de si é a descoberta, sob a superfície da pele de uma profunda sensibilidade interna. Contornando ou se desviando das normas até então incorporadas, o sujeito contemporâneo descobre o espaço interior de seu corpo" (ANDRIEU, 2014, P. 159).

Esse aprofundamento se revela pela emergência de novas sensações do corpo vivo. Nesse sentido, as técnicas de corpo interrogam as condições de aprendizagem dos gestos no corpo vivo e no corpo vivido. Bernard Andrieu mostra inúmeros exemplos dessas experiências que ele reporta ao corpo vivo (le corps vivant) por meio dos relatos em primeira pessoa que expõem a imersão no corpo.

A arte de mergulhar no corpo exige dispositivos imersivos. O dispositivo é um lugar, uma instância, um meio, como por exemplo, um museu ou um espetáculo, no qual a eficácia performativa é suficiente para produzir um efeito inédito no corpo. Esse efeito é uma experiência imersiva pelas emoções, imagens e sensações produzidas de maneira voluntária e involuntária.

A emersão (s'émerser) é uma atividade interna do cérebro e desencadeia a emergência até os níveis conscientes. De acordo com o autor, há uma diferença entre a emersão e a enação (énaction) de Francisco Varela pois na primeira não se visa uma saída cognitiva uma vez que se admite a diferença qualitativa entre o que é ativado no cérebro pelo corpo vivo e o que é percebido em níveis conscientes. Trata-se de uma ontologia da descontinuidade em uma epistemologia do afastamento criativo entre o corpo vivo e o corpo vivido.

Importante registrar que há sempre uma diferença entre o que se produz internamente em nosso corpo e sua expressão traduzida em imagem, som, vibração e cor, sendo a expressão sempre qualitativamente menos intensa. Assim, aceitar não ter o controle sobre tudo, deixar-se imergir para fazer emergir em si novas experiências e sensações exige uma disposição para liberar o potencial humano por meio do corpo e intensificar a expressão corporal.

A partir dessa proposição Bernard Andrieu nos oferece novas sensações, expressões, paisagens para a filosofia do corpo que ultrapassam o primado da filosofia da linguagem e que permite fazer emergir o corpo vivo e suas sensações. Assim, podemos quem sabe sair do campo da representação do corpo para a experiência do corpo vivo. Trata-se de uma amplificação do corpo vivido tal qual a fenomenologia da percepção nos apresenta, com ênfase nos traços do vivo em mim, sejam esses traços crônicos, traumatizantes ou prazerosos.

O dispositivo imersivo produz modalidades inéditas baseadas nas sensações internas, notadamente no estado de vertigem em suas múltiplas formas: a vertigem do amor, do orgasmo, da dor, da liberdade, da dança, do transe, dos esportes radicais. Porém o método de descrição, de narração e de expressão dessa vertigem é o método do afastamento entre o vivo e o vivido, ou 
seja, entre o que acontece de fato no corpo e aquilo que pela linguagem podemos expressar. Destaca-se aqui o trabalho de criação artística, por exemplo, como uma possibilidade de se imergir.

A obra de Bernard Andrieu nos dá a vertigem, nos mergulha na intimidade das sensações para reconhecer a distância entre o que se passa no corpo e aquilo que podemos descrever em terceira pessoa sob o domínio da linguagem. Mas, sentir a vertigem é também produzir novos dispositivos, novos esquemas corporais e outras possibilidades de expressão em um registro no qual temos no mínimo dificuldade de separar o que se produz em nós e o que provém do mundo. "Nossas sensações se avivam e nossa empatia se ativa inconscientemente" (ANDRIEU, 2014, p. 194).

De acordo com o autor "o corpo é o buraco negro delimitado por orifícios os quais apenas exaltamos o erotismo de suas superfícies (...). Voltando-se à pele pela sensibilidade intima, a vertigem revela em nós uma cartografia das cavernas interiores" (ANDRIEU, 2014, 195). E é esse continente que o filosofo francês nos convida a percorrer em seu livro vertiginoso, por assim dizer.

Compreendo que a obra "Dar-se em Vertigem: as artes imersivas"amplifica as abordagens em filosofia do corpo, incluindo as de natureza fenomenológica que temos conhecimento ao mergulhar na sensorialidade, reconhecendo a estesia do corpo vivo e seu distanciamento da expressão. Tal lacuna, tal distância, tal impossibilidade de tudo dizer e de tudo descrever não é uma barreira, um impedimento à criação, ao contrário, é um desafio a se permitir explorar novas sensações inclusive a perda de sentidos, em particular àqueles das normas e da linguagem instituída.

\section{REFERÊNCIAS}

1. ANDRIEU, Bernard. Donner le vertige: les arts immersifs. Liber: Montreal, 2014.

2. A nova Filosofia do corpo. Lisboa: Instituto Piaget, 2004.

3. AUSTER, Paul. Diário de Inverno. Tradução de Paulo Henriques Brito. São Paulo: Companhia das Letras, 2014.

4. MERLEAU-PONTY, Maurice. La Nature. Notes de cours au Collège de France. Texte établi par Dominique Séglard. Paris : Seuil, 1995. 